\title{
DIETARY OVERLAP IN GIANT SALAMANDERS (DICAMPTODON): APPLYING NULL MODELS TO RESOURCE PARTITIONING
}

\author{
Craig A. Steele ${ }^{1}$ and Colin Brammer ${ }^{2}$
}

\begin{abstract}
Aвstract.-We examined stomach contents of preserved specimens of larval Pacific giant salamander (Dicamptodon tenebrosus) and Cope's giant salamander (D. copei) collected from sympatric and allopatric stream populations. The dietary components of these specimens were used to calculate dietary overlap between the 2 species and to determine if changes in overlap existed between sympatric and allopatric populations. To statistically test overlap values, a randomization algorithm was used to construct a simulated data matrix (i.e., null model) in order to compare observed values of dietary overlap to a distribution of overlap values from the null model. Significant levels $(P<0.05)$ of dietary overlap occurred in all cases of sympatry as well as allopatry. Average dietary overlap in sympatry was significantly lower than in allopatry, suggesting a dietary shift when in sympatry to reduce competition. Diet composition also differed between sympatric and allopatric populations of each species, further suggesting a partitioning of food resources by one or both species when in the presence of its congener.
\end{abstract}

Key words: Dicamptodon copei, Dicamptodon tenebrosus, niche, competition, resource partitioning, community ecology, predation.

A central objective of community ecology is to explain the structure of species assemblages and the interactions of organisms within those assemblages (Connell 1983, Roughgarden and Diamond 1986). Measuring resource overlap within a species assemblage is one way to examine organization within a community. However, quantifying resource overlap is difficult and the topic has received extensive study including critiques of original overlap indices (Horn 1966), suggested improvements for overlap indices (Hurlbert 1978, Lawlor 1980a), and development of multidimensional overlap indices (Pianka 1973) and techniques for inferring competition from indices rather than from simple resource overlap (Slobodchikoff and Schulz 1980). Overlap indices range from 0 (no overlap in any of the measured resources) to 1 (compete overlap in all measured resources) and are inherently difficult to interpret because the value of the index is influenced by the number of species compared and the number of resources measured. Overlap values by themselves cannot be used to directly determine the exact degree to which 2 species are competing or if the degree of overlap is significant (Sale 1974). For this reason, use of appropriate statistical models is necessary when comparing resource overlap between organisms.
Null models are currently favored to test for niche overlap because they provide an appropriate null hypothesis against which observed values of overlap can be compared (Caswell 1977). Null models generate a simulated data matrix based on the observed data with which a statistical critical value for the overlap index can be determined. In this study we examine dietary overlap by comparing observed patterns of resource utilization to null models of food utilization for 2 species of stream-breeding salamander in the Pacific Northwest: Dicamptodon tenebrosus and D. copei.

Dicamptodontid salamanders are often the most abundant vertebrate predators in mountainous streams in the Pacific Northwest of North America and can comprise $>90 \%$ of predator biomass (Murphy and Hall 1981). These salamanders consume a wide variety of prey items (Johnson and Schreck 1969, Parker 1994) and are thought to be opportunistic feeders (Antonelli et al. 1972). Although the 2 species in this study have different life histories $(D$. tenebrosus usually transform into terrestrial adults while $D$. copei rarely metamorphose [Nussbaum 1970]), morphological differences between larvae are subtle and can be difficult to differentiate in the field. It has been predicted that minor morphological changes

${ }^{1}$ School of Biological Sciences, Washington State University, Pullman, WA 99164.

${ }^{2}$ Department of Biology, Utah State University, Logan, UT 84322. 
between species are sufficient to accommodate significant differences in resource partitioning (Schoener 1974), and recent studies have supported this hypothesis (Adams 2000, Adams and Rohlf 2000). The ranges of these species overlap in southwestern Washington and northwestern Oregon. Streams in this area may contain one or both species, thereby providing an opportunity to examine the use and allocation of prey resources between the 2 species. We calculated niche overlap indices to test for differences in dietary overlap between sympatric and allopatric populations. In addition, dietary composition of sympatric and allopatric individuals was described and compared to determine if either species exhibited a dietary shift between allopatry and sympatry.

\section{Methods}

Specimens of D. tenebrosus and D. copei were collected from June through August during 1998 and 1999 from headwater streams in the Cascade Mountains of south central Washington as part of a previous study on their habitat relationships (Steele et al. 2002). Sympatric streams had both species present during at least 1 year of sampling, and allopatric streams had only 1 of the species present in both years. All streams were located within 30 $\mathrm{km}$ of each other (Steele et al. 2002) and were located at similar elevations (mean elevation $=1780 \mathrm{~m}, s=521$ ). Because of the similarity in geographic location and elevation, we assume that these streams were experiencing similar insect communities when the specimens were collected. Specimens collected in sympatry in 1998 included 43 D. copei and 39 D. tenebrosus from 8 streams. Two of the original 8 streams that were resampled in 1999 did not have sufficient captures to be included in the study, but specimens were available from 2 nearby additional streams and were substituted instead. In 1999 sympatric specimens included 35 D. copei and 31 D. tenebrosus. Specimens collected in allopatry in 1998 included $85 \mathrm{D}$. copei from 11 streams and 17 D. tenebrosus from 4 streams. Specimens collected in allopatry in 1999 included $67 \mathrm{D}$. copei from 9 of the same streams and 45 D. tenebrosus from 3 of the same streams. Specimens were not available in 1999 from the remaining allopatric stream populations.
The entire digestive tract of each specimen was removed and placed in $95 \%$ ethanol until the contents could be identified. Each digestive tract was examined "blind" such that the observer did not know which species was being examined. We removed and sorted all contents from the entire digestive tract. Gut contents were identified to the lowest taxonomic unit possible (i.e., family) and counted, but some items, such as oligochaete worms and gastropods, could not be identified lower than class. We also categorized prey items according to different developmental stages (e.g., larvae, pupa, adult) when applicable. Because many of the food items were incomplete or partially digested, we did not attempt to determine size or volume of the items. We did not include internal parasites, such as helminths, in the data analysis. Individuals not containing food items were excluded from the analysis.

To calculate dietary overlap we first determined the proportion of the total diet constituted by each prey item for a population of salamanders. This was done by summing the total number of a particular prey item across all specimens collected from a population and dividing by the total number of prey items recorded from all specimens in the same population. This method prevented bias in the data if 1 specimen had a particularly high number of a rare prey type. Dietary overlap was then estimated with the program EcoSim 7.0 (Gotelli and Entsminger 2004) which calculates Pianka's (1973) overlap index using Lawlor's (1980b) 3rd randomization algorithm (RA3). The RA3 algorithm has been shown to have desirable statistical properties for detecting nonrandom niche overlap patterns (Winemiller and Pianka 1990, Gotelli and Entsminger 2004). EcoSim not only generates a niche overlap value from the observed data, but produces a statistical critical value based on a null distribution of randomized raw data to test the significance of the overlap value. The RA3 algorithm retains values for niche breadth (i.e., degree of specialization) but randomly reshuffles these values, including any zeros, among prey categories for each species. This permutation step was repeated for a total of 1000 simulations. The combined results of all simulations were used to create a null model of the data, or in other words, the overlap indices from each permutation were used to generate a distribution of overlap values based on randomized data matrices 
TABLE 1. Dietary overlap values between sympatric Dicamptodon copei and D. tenebrosus. A sufficient number of specimens was not available from streams 7 and 8 in 1999, and these were substituted with specimens collected in sympatry from nearby streams 9 and 10. In every case, observed dietary overlap values were significantly higher than the simulated distribution of values based on null models.

\begin{tabular}{|c|c|c|c|c|c|}
\hline \multirow[b]{2}{*}{ Stream } & \multicolumn{2}{|c|}{ Number of specimens } & \multirow{2}{*}{$\begin{array}{c}\text { Observed } \\
\text { dietary overlap }\end{array}$} & \multirow{2}{*}{$\begin{array}{c}\text { Mean of simulated } \\
\text { indices (variance) }\end{array}$} & \multirow[b]{2}{*}{$P$} \\
\hline & D. copei & D. tenebrosus & & & \\
\hline \multicolumn{6}{|c|}{ Overlap Values in Sympatry For 1998} \\
\hline 1 & 5 & 5 & 0.55 & $0.09(0.009)$ & 0.01 \\
\hline 2 & 4 & 9 & 0.53 & $0.09(0.009)$ & 0.01 \\
\hline 3 & 5 & 2 & 0.59 & $0.06(0.008)$ & 0.01 \\
\hline 4 & 3 & 5 & 0.62 & $0.06(0.01)$ & 0.01 \\
\hline 5 & 7 & 7 & 0.63 & $0.10(0.008)$ & $<0.0001$ \\
\hline 6 & 9 & 2 & 0.46 & $0.06(0.007)$ & 0.008 \\
\hline 7 & 3 & 5 & 0.41 & $0.14(0.006)$ & 0.02 \\
\hline 8 & 7 & 4 & 0.34 & $0.09(0.008)$ & 0.04 \\
\hline $\operatorname{Mean}\left( \pm s_{\bar{x}}\right)$ & & & $0.52( \pm 0.037)$ & & \\
\hline \multicolumn{6}{|c|}{ OVERLAP VALUES IN SyMPATRY FOR 1999} \\
\hline 1 & 3 & 2 & 0.50 & $0.14(0.006)$ & 0.003 \\
\hline 2 & 3 & 7 & 0.9 & $0.05(0.01)$ & $<0.0001$ \\
\hline 3 & 2 & 5 & 0.82 & $0.11(0.009)$ & $<0.0001$ \\
\hline 4 & 3 & 2 & 0.47 & $0.06(0.01)$ & 0.02 \\
\hline 5 & 12 & 2 & 0.67 & $0.06(0.01)$ & 0.001 \\
\hline 6 & 5 & 4 & 0.42 & $0.08(0.008)$ & 0.02 \\
\hline 9 & 3 & 7 & 0.79 & $0.08(0.008)$ & $<0.0001$ \\
\hline 10 & 4 & 2 & 0.52 & $0.1(0.008)$ & $<0.0001$ \\
\hline $\operatorname{Mean}\left( \pm s_{\bar{x}}\right)$ & & & $0.64( \pm 0.065)$ & & \\
\hline
\end{tabular}

that retained qualitative characteristics of the original data. We then used this null distribution of the overlap index values to test for statistical significance of the observed overlap index value.

We calculated dietary overlap in sympatry within each stream for both years that specimens were available. Allopatric niche overlap was calculated by combining total gut contents from all allopatric populations of 1 species and comparing to similarly combined data from allopatric streams of the other species. One unavoidable side effect of pooling dietary data from multiple allopatric populations is that data from streams with a greater number of captures are over-represented. However, by replicating the study over a 2 -year period we hoped to minimize any bias incurred through pooling allopatric dietary data. A 1-sample $t$ test was used to test differences between overlap values of sympatric and allopatric populations of a single species. In addition to calculating overlap, we performed chi-square analysis on raw count data of prey items to test for dietary shifts of a species in sympatry and allopatry. To eliminate categories with zeros or small counts, we collapsed food categories to the level of order. We used 4 main insect orders (Ephemeroptera, Trichoptera, Plecoptera, and Diptera), which comprised at least $85 \%$ of food items, along with a 5 th category which contained a combination of rare and miscellaneous food items.

\section{RESUlTs}

Dicamptodon copei and D. tenebrosus collected in sympatry during 1998 had significant dietary overlap values $(P<0.05)$ ranging from 0.34 to 0.63 (Table 1$)$. The average overlap value for all streams in 1998 was $0.52 \pm 0.037$. Specimens collected from streams in $1999 \mathrm{had}$ slightly higher values ranging from 0.42 to 0.82 . Overlap values were also significant in all streams and average overlap in streams for 1999 equaled $0.64 \pm 0.065$. The degree of overlap measured between years was not significantly different (paired $t$ test; $t=1.4979$, $\mathrm{df}=7, P=0.1778)$.

Specimens collected in allopatry during 1998 had a significant $(P<0.0001)$ overlap index of 0.72 (Table 2 ), which was significantly higher $(t=-5.5312$, df $=7, P=0.0009)$ than overlap in sympatry. Specimens collected in allopatry during 1999 also had a significant $(P$ 
TABLE 2. Dietary overlap values for allopatric populations of Dicamptodon copei and D. tenebrosus sampled in 1998 and 1999. Observed overlap values in both years were significantly higher than the simulated distribution of values based on null models.

\begin{tabular}{lccccc}
\hline Year & $\begin{array}{c}\text { D. copei } \\
(n)\end{array}$ & $\begin{array}{c}\text { D. tenebrosus } \\
(n)\end{array}$ & $\begin{array}{c}\text { Observed } \\
\text { dietary overlap }\end{array}$ & $\begin{array}{c}\text { Mean of simulated } \\
\text { indices (variance) }\end{array}$ & $P$ \\
\hline 1998 & 85 & 17 & 0.72 & $0.18(0.006)$ & $<0.0001$ \\
1999 & 67 & 45 & 0.89 & $0.1(0.009)$ & $<0.0001$ \\
\hline
\end{tabular}

$<0.0001)$ overlap index of 0.89 , which was also higher $(t=-3.9206, \mathrm{df}=7, P=0.0057)$ than the overlap value for specimens in sympatry during the same year.

Simulated overlap values (Tables 1, 2) were generally low (0.06-0.18) and were probably caused by the large number of fine-scale categories ( 55 based on taxonomy and developmental stages) used to group prey items. Randomization of the observed data from a large number of resource categories is most likely responsible for low overlap values in the simulated data matrices.

A chi-square comparison of diet composition between sympatric and allopatric individuals of each species (Table 3) showed that diets were different between the groups for both species in both years. Diets of allopatric $D$. tenebrosus differed from those of D. tenebrosus occurring in the presence of $D$. copei for $1998\left(\chi^{2}=21.6, \mathrm{df}=4, P=0.0002\right)$ and 1999 $\left(\chi^{2}=23.9, \mathrm{df}=4, P=0.0001\right)$. Diets of allopatric $D$. copei also differed from those of $D$. copei occurring in the presence of $D$. tenebrosus for $1998\left(\chi^{2}=30.15, \mathrm{df}=4, P<0.0001\right)$ and $1999\left(\chi^{2}=122.0, \mathrm{df}=4, P<0.0001\right)$.

\section{Discussion}

Our results show that dietary overlap between $D$. copei and D. tenebrosus is high in allopatry as well as in sympatry. However, the lower levels of overlap in sympatric populations suggest competition and allocation of food resources between the 2 species when they occupy the same streams. This is also evidenced by the difference in diets between sympatric and allopatric populations within a species. The higher overlap values in allopatry suggest that these species consume more similar diets when they are the sole species in a stream. In sympatry, however, competition may result in partitioning of food resources and lower overlap values. Shifts in microhabitat use due to presence of congeners has been demonstrated in streambank communities of salamanders (Krzysik 1979); other studies have examined dietary overlap in salamanders to test for competition (Brophy 1980), but additional examples of shifts in salamander dietary overlap are uncommon.

The reduction of overlap in sympatry along with differences in diet between sympatric and allopatric populations of each species suggests a shift by either 1 or both species to reduce competition for food resources in response to the presence of its congener. An alternative explanation for lower dietary overlap in sympatry may be that sympatric individuals utilize different microhabitats and thereby experience slightly different insect species compositions. While these 2 species are quite similar morphologically, larval $D$. tenebrosus tend to be more robust than $D$. copei of similar size (Nussbaum 1970). The larger size of D. tenebrosus may allow it to exclude $D$. copei from some microhabitats. In this case, the perceived reduction in dietary overlap in sympatry would be an artifact resulting from partitioning of foraging locales. Data on microhabitat use of these species are currently unavailable and would provide more insight on their use and allocation of resources.

It is unclear how long these species have existed in sympatry, but phylogeographic studies of the genus suggest relatively distant genetic separation of the 2 species (Daugherty et al. 1983, Good 1989, Steele et al. 2005). If the 2 species have been competing for dietary resources in sympatry over many generations, then one would expect partitioning of those resources among the species. Because measures of food resource availability in the environment were not available from streams where specimens were collected, we were not able to determine if either species was consuming prey items selectively or in proportion to their availability. Specimens collected in sympatry would 
TABLE 3. Count data of prey items consumed by sympatric and allopatric populations of Dicamptodon tenebrosus and D. copei sampled in 1998 and 1999. In order to eliminate zeros from the data matrix for the chi-square analysis, prey categories were collapsed to the 4 most common insect orders that comprised $>85 \%$ of the diet. Values in parentheses indicate the percent utilization of each prey category.

\begin{tabular}{|c|c|c|c|c|}
\hline \multirow[b]{2}{*}{ Order } & \multicolumn{2}{|c|}{ Sympatric } & \multicolumn{2}{|c|}{ Allopatric } \\
\hline & D. copei & D. tenebrosus & D. copei & D. tenebrosus \\
\hline \multicolumn{5}{|l|}{1998} \\
\hline Ephemeroptera & $66(17.98)$ & $92(22.17)$ & $137(18.2)$ & $31(23.85)$ \\
\hline Tricoptera & $144(39.24)$ & $97(23.37)$ & $321(42.7)$ & $46(35.38)$ \\
\hline Plecoptera & $73(19.89)$ & $83(20.00)$ & $74(9.8)$ & $31(23.85)$ \\
\hline Diptera & $41(11.17)$ & 117 (28.19) & $145(19.3)$ & $12(9.23)$ \\
\hline Othera & $43(11.72)$ & $26(6.27)$ & $75(10.0)$ & $10(7.69)$ \\
\hline \multicolumn{5}{|l|}{1999} \\
\hline Ephemeroptera & $119(23.43)$ & $136(22.22)$ & $85(10.6)$ & $127(25.1)$ \\
\hline Tricoptera & $165(32.48)$ & $113(18.46)$ & $167(20.9)$ & $105(20.8)$ \\
\hline Plecoptera & $91(17.91)$ & $96(15.69)$ & $97(12.2)$ & $45(8.9)$ \\
\hline Diptera & $93(18.3)$ & $214(34.97)$ & $352(44.1)$ & $151(29.8)$ \\
\hline Other & $40(7.87)$ & $53(8.66)$ & $97(12.2)$ & 78 (15.4) \\
\hline
\end{tabular}

ancludes Acari, Amphipoda, Aphidae, Araneae, Carabidae, Cladocera, Coleoptera, Crustaceans, Curculionidae, Decapoda, Diplopoda, Gastropoda, Hemiptera, Homoptera, Hymenoptera, Isopoda, Lampyridae, Lepidoptera, Megaloptera, Nematomorpha, and Oligochaeta.

have experienced the same insect assemblage, but because streams were sampled over the course of a summer, different streams may have had different available food resources. Diet composition between years sometimes varied considerably for the same populations (Table 3) suggesting temporal changes in the abundance of prey items. Therefore, it is possible that some component of the overlap indices calculated for sympatric and allopatric populations was not entirely indicative of the degree of competition between the 2 species but was influenced by the abundance of prey in those environments. These salamanders are thought to be opportunistic feeders, eating a proportional equivalent of what is available in a stream (Antonelli et al. 1972). Parker (1994), on the other hand, showed that there was no correlation between relative abundance of prey type in a stream and their relative abundance in the salamander diet, suggesting that Dicamptodon may feed preferentially on prey items. It is therefore plausible that either 1 or both species could change diets in the presence of the other to reduce competition for food items. However, without information about relative prey abundance at the time of specimen collection, our results are limited to presentation of overlap values without the context of an electivity index (Chesson 1978). Because many of the prey items examined in this study were either incomplete or in a state of advanced digestion we are unable to provide data on whether either Dicamptodon species partitioned prey items by size. Previous studies have shown that salamanders are likely to partition prey resources by size, feeding preferentially on prey of a certain size rather than prey from a specific taxon (Adams 2000, Adams and Rohlf 2000). Salamander diets can also change ontogenetically such that larger individuals consume larger prey while ignoring smaller more numerous prey (Lynch 1985, Maglia 1996). Our inability to collect accurate size data on prey items precluded our ability to test the effect of size-based partitioning of prey.

\section{ACKNOWLEDGMENTS}

We collected specimens under Washington scientific collecting permit 98-173-C. J.R. Mendelson, III and C. von Dohlen provided lab space and equipment. S. Mech provided statistical advice. Earlier versions of the manuscript benefited from comments by A. Storfer, P. Verrell, and members of their laboratories at Washington State University. Comments by 2 anonymous reviewers also improved the quality of the manuscript. Specimens and their dietary contents are housed at the Arlington Collection of Vertebrates (A55789-A55077), University of Texas.

\section{Literature Cited}

ADAMS, D.C. 2000. Divergence of trophic morphology and resource use among populations of Plethodon cinereus 
and Plethodon hoffmani in Pennsylvania: a possible case of character displacement. Pages 383-394 in R.C. Bruce, R.G. Jaeger, and L.D. Houck, editors, The biology of plethodontid salamanders. Kluwer Academic / Plenum Publishing, New York.

AdAms, D.C., AND F.J. RohlF. 2000. Ecological character displacement in Plethodon: biomechanical differences found from a geometric morphometric study. Proceedings of the National Academy of Sciences 97:4106-4111.

Antonelli, A.L., R.A. Nussbaum, and S.D. Smith. 1972. Comparative food habits of four species of streamdwelling vertebrates (Dicamptodon ensatus, D. copei, Cottus tenuis, Salmo gairdneri). Northwest Science 46:277-289.

Brophy, T.E. 1980. Food habits of sympatric larval Abystoma tigrinum and Notophthalmus viridescense. Journal of Herpetology 14:1-6.

CASWELl, H. 1977. Community structure: a neutral model analysis. Ecological Monographs 46:327-354.

Chesson, J. 1978. Measuring preference in selective predation. Ecology 59:211-215.

Connell, J.H. 1983. On the prevalence and relative importance of interspecific competition: evidence from field experiments. American Naturalist 122:661-696.

Daugherty, C.H., F.W. Allendorf, W.W. Dunlap, and K.L. Knudsen. 1983. Systematic implications of geographic pattern of genetic variation in the genus Dicamptodon. Copeia 1983:679-691.

GooD, D.A. 1989. Hybridization and cryptic species in Dicamptodon (Caudata: Dicamptodontidae). Evolution 43:728-744.

Gotelli, N.J., AND G.L. EnTSMinger. 2004. EcoSim: null models software for ecology, version 7. Acquired Intelligence Inc. and Kesey-Bear. Jericho, VT. Available from: http://garyentsminger.com/ecosim/index.htm

HonN, H.S. 1966. Measurement of "overlap" in comparative ecological studies. American Naturalist 100:419-424.

HurlberT, S.H. 1978. The measurement of niche overlap and some relatives. Ecology 59:67-77.

Johnson, C.R., AND C.B. SCHRECK. 1969. Food and feeding of larval Dicamptodon ensatus from California. American Midland Naturalist 81:280-281.

KrzYsIK, A.J. 1979. Resource allocation, coexistence, and the niche structure of a streambank salamander community. Ecological Monographs 49:173-194.
LAWLOR, L.R. 1980a. Overlap, similarity, and competition coefficients. Ecology 61:245-251.

.1980b. Structure and stability in natural and randomly constructed competitive communities. American Naturalist 116:394-408.

MagLiA, A.M. 1997. Ontogeny and feeding ecology of the red-backed salamander, Plethodon cinereus. Copeia 1996:576-586.

MuRPhy, M.L., AND J.D. HALL. 1981. Varied effects of clearcut logging on predators and their habitat in small streams of the Cascade Mountains, Oregon. Canadian Journal of Fisheries and Aquatic Sciences 38:137-145.

Nussbaum, R.A. 1970. Dicamptodon copei, n.sp., from the Pacific Northwest, USA. (Amphibia: Caudata: Ambystomatidae). Copeia 1970:506-514.

Parker, M.S. 1994. Feeding ecology of stream-dwelling Pacific giant salamander larvae (Dicamptodon tenebrosus). Copeia 1994:705-718.

PIANKA, E.R. 1973. The structure of lizard communities. Annual Review of Ecology and Systematics 4:53-74.

Roughgarden, J., And J. Diamond. 1986. The role of species interactions in community ecology. Pages 333-343 in J.M. Diamond and T.J. Case, editors, Community ecology. Harper and Row, New York.

SALE, P.F. 1974. Overlap in resource use, and interspecific competition. Oecologia 17:245-256.

Schoener, T.W. 1974. Resource partitioning in ecological communities. Science 185:27-39.

Slobodchikoff, C.N., AND W.C. Schulz. 1980. Measurements of niche overlap. Ecology 61:1051-1055.

Steele, C.A., E.D. Brodie, Jr., and J.G. MacCracken. 2002. Influence of forest age on densities of Cope's and Pacific giant salamanders. Northwest Science 76:347-352.

Steele, C.A., B.C. Carstens, A. Storfer, and J. Sullivan. 2005. Testing hypotheses of speciation timing in Dicamptodon copei and Dicamptodon aterrimus (Caudata: Dicamptodontidae). Molecular Phylogenetics and Evolution 36:90-100.

Winemiller, K.O., And E.R. PianKa. 1990. Organization in natural assemblages of desert lizards and tropical fishes. Ecological Monographs 60:27-55.

Received 20 December 2004 Accepted 26 April 2005 